\title{
A solidão dos trabalhadores: sociabilidade contemporânea e degradação do trabalho
}

\author{
Luci Praun \\ Universidade Estadual de Campinas (Campinas, SP, Brasil) e \\ Universidade Metodista de São Paulo (São Paulo, SP, Brasil)
}

Este artigo tem por objetivo problematizar as relações de trabalho e a sociabilidade que emergem entre as décadas de 1970-1980. Questiona, neste contexto, se estaríamos diante de condições e situações de trabalho mais adoecedoras que aquelas vivenciadas no período de predomínio do taylorismo-fordismo. Salienta, com base neste questionamento, os mecanismos presentes na sociabilidade contemporânea capazes de converter os locais de trabalho em espaços de degradação dos laços de solidariedade, de adoecimento físico e mental, assim como de descarte dos trabalhadores adoecidos pelo trabalho.

Palavras-chave: Precarização do trabalho, Trabalho e adoecimento, Mundo do trabalho.

Workers' isolation: contemporary sociability and deterioration of work

This article aims to problematize the relationships between work and sociability that emerged between the 1970's and 1980's. It questions whether today's working conditions and situations are more illness-causing than those of the period when Taylorism and Fordism prevailed. Based on this questioning, the article also points out the mechanisms present in contemporary sociability capable of turning workplaces into spaces of degradation of solidarity bonds, into spaces of physical and mental illness, leading to the abandonment of ill workers.

Keywords: Deterioration of working conditions, Work and illness, World of work.

\section{Introdução}

relação entre trabalho e processos de adoecimento não é um fenômeno novo. Tampouco
se pode dizer que são recentes as pesquisas sobre o tema. São bastante conhecidos os
estudos do médico italiano Bernardino Ramazzini, publicados pela primeira vez em 1700 . Em
seu livro, As doenças dos trabalhadores, Ramazzini (2000) descreveu detalhadamente o conjunto
de fatores que compunha condições de trabalho específicas, relacionadas a diferentes
atividades, estabelecendo, assim, o nexo entre trabalho e adoecimento. Tinha por hábito visitar
os locais de trabalho, observar como os operários executavam seus ofícios, além de escutá-los
atentamente.

Buscava, ao seu modo, algo que até hoje persegue parte significativa daqueles que se dedicam aos estudos do trabalho: desvelar os diferentes fios que tecem a trama das relações de exploração, explicitando as diversas configurações assumidas pelo trabalho e seu impacto na saúde e vida dos trabalhadores. Almejava, sobretudo, conhecer as condições sociais geradoras das enfermidades para poder intervir, prevenindo e curando as doenças que acometiam aqueles que, fruto de sua posição social e ofício, viam-se obrigados a submeter-se a condições degradantes de trabalho. Suas pesquisas tornaram-se referência para uma série de investigações posteriores.

No século seguinte à publicação da obra de Ramazzini, a expansão da indústria impôs ao trabalho novos traços. Foi do centro dessas mudanças, em Manchester, que, em meio à crescente movimentação operária, Friedrich Engels (2010) produziu um detalhado estudo sobre as condições de vida do operariado. Diferentemente do proposto por Ramazzini, o foco de 
Engels, em A formação da classe trabalhadora na Inglaterra ${ }^{1}$, não foram os processos de adoecimento com nexo laboral. Esbarrar na questão da saúde do operariado foi, para o autor, entretanto, inevitável, uma vez que o nó da relação entre trabalho e adoecimento, ao longo da história da humanidade, encontra-se nas diferentes formas assumidas pela exploração do trabalho.

É essa a perspectiva e importante contribuição desenhada por Engels ao abordar, em inúmeras passagens do livro, as condições de vida e de trabalho que degradam e fazem homens, mulheres e crianças padecerem. Para Engels, os processos de trabalho e adoecimento não se concebem enquanto resultados isolados e ocasionais. $\mathrm{O}$ autor admite que o desenvolvimento do capitalismo, com base nas contradições que lhe são próprias, vai reinventando as regras de seu funcionamento, muitas vezes impondo limites ao processo de exploração. Esses limites, entretanto, não são resultado do desenvolvimento social linear, de uma evolução progressiva do processo civilizatório. Se a reinvenção das normas de funcionamento do sistema não escapa à dinâmica de uma ordem social cujo fundamento não consegue desvencilhar-se da necessidade de aprofundar permanentemente a exploração do trabalho, elas também se deparam com as barreiras erguidas pela resistência e luta daqueles que trabalham (Marx, 2013). Assim, ainda que o século XIX tenha se configurado como palco de organização e luta dos trabalhadores e que, em parte importante do século XX, tenham ocorrido avanços na conquista de direitos sociais e trabalhistas, o trabalho manteve-se como fonte inesgotável de diferentes formas de sofrimento e adoecimento.

São contradições como essas que fizeram com que, ao longo do século XX, principalmente a partir da sua segunda metade, tenham se tornado mais recorrentes os estudos sobre o impacto da organização do trabalho na saúde dos trabalhadores. Especialmente nos países centrais do capitalismo, entre os anos 1950-1970, onde prosperou o Estado de Bem-Estar Social, as preocupações voltaram-se para a insatisfação gerada pela rotina e monotonia instituídas pelo taylorismo-fordismo. Conforme destaca Yves Clot (2010, p. 218), parte das pesquisas então desenvolvidas passou a ressaltar a "dimensão negativa" do trabalho, iluminando aspectos das condições de sua realização capazes de impactar a saúde mental dos assalariados.

Louis Le Guillant (2006), psiquiatra francês e percussor dos estudos de psicopatologia do trabalho, juntamente com outros pesquisadores, desenvolveu nos anos 1950 um detalhado estudo sobre como a fadiga nervosa atingia trabalhadores dentro e fora das fábricas. A cadência de gestos simples e repetitivos, associada ao controle, ritmo e intensidade crescentes do trabalho e também às exigências de atenção e precisão, estaria na origem dos processos de adoecimento dos trabalhadores.

Nos anos 1970, como resultado de sua imersão nas linhas de montagem da Citroën, na França, o sociólogo Robert Linhart (1980) descreveu o dia a dia do trabalho sob o predomínio do taylorismo-fordismo. Conforme o pesquisador, não era incomum que um recém-contratado:

[pedisse] as suas contas ao fim do primeiro dia de trabalho, enlouquecido pelo barulho, pelos clarões, pelo monstruoso prolongamento do tempo, pela dureza do trabalho indefinidamente repetido, pelo autoritarismo dos chefes e a secura das ordens, e a sombria atmosfera de prisão que gela a oficina (p. 23).

Na mesma década, em 1979, em meio à explosão grevista no ABC Paulista, uma reportagem de jornal advertia sobre o alto índice de metalúrgicos brasileiros que se aposentavam por invalidez antes dos 50 anos. "Neurose, pressão alta acompanhada de derrame cerebral e moléstias da coluna vertebral são as doenças profissionais responsáveis pela maior parte das aposentadorias por invalidez", indicava a matéria (ABC, 1979).

1 A primeira publicação da obra data de 1845 . 
Nos anos anteriores à reportagem, em 1977 e 1978, o cotidiano dos operários da maior automobilística instalada na região, a Volkswagen, pôde ser, em parte, conhecido pelos relatos obtidos por Celso Frederico (1979) junto a um grupo de operários, que mencionavam o "clima enervante", a pressão constante da chefia, o ritmo acelerado de trabalho. Falavam ainda das pequenas burlas, sabotagens na produção, que sinalizavam a insatisfação e o rastro para a explosão grevista que atravessou os anos de 1978 a $1980^{2}$.

Ainda assim, pode-se afirmar que foram muito poucas as iniciativas das organizações sindicais voltadas à temática da saúde dos trabalhadores, especialmente tratando-se de aspectos relacionados à saúde mental. Para além do preconceito que sempre rondou a questão por muito tempo (e mantém-se assim em grande medida), os processos de adoecimento mental foram persistentemente compreendidos como algo relacionado à esfera individual e, portanto, fora do escopo de ação das entidades representativas, voltadas essencialmente às questões coletivas.

Evidenciando o equívoco da perspectiva que insiste em reduzir os processos de adoecimento mental à esfera individual, no Brasil foi grande a receptividade, nos anos 1980, década marcada pela forte mobilização social e reorganização do movimento sindical, ao livro de Christophe Dejours, A loucura do trabalho. Apoiado nos pressupostos da psicopatologia do trabalho, o autor propõe uma inversão: o aprisionamento do corpo pressupõe o aprisionamento mental. O corpo disciplinado é aquele para o qual o trabalho tende a expressar, em seu sentido pleno, a insatisfação e o sofrimento, portas de entrada para o adoecimento. O sofrimento, que tem na forma assumida pela organização do trabalho seu suporte, "...começa quando o homem no trabalho já não pode fazer nenhuma modificação na sua tarefa no sentido de torná-la mais conforme suas necessidades fisiológicas e seus desejos psicológicos, isto é, quando a relação homem-trabalho é bloqueada" (Dejours, 1992, p. 133).

É oportuno observar como Dejours destaca nessa obra que as margens para uma "vivência subjetiva", para o prazer do trabalho, só encontravam espaço de efetivação em profissões específicas: aquelas que exigiam habilidade artesanal, as relacionadas à pesquisa, as inseridas no campo das profissões liberais, entre poucas outras (1992, p. 135).

O taylorismo-fordismo havia, de fato, hierarquizado a organização do trabalho, restringindo à gerência e à engenharia as atividades de elaboração, restando ao corpo de operários, assim como aos trabalhadores administrativos médios, a execução de tarefas fragmentadas, simplificadas e repetitivas ao máximo. Como resultado da generalização da aplicação da gerência científica, pôde-se observar, ao final dos anos 1960, a crescente insatisfação com o trabalho, expressa, entre outras formas, pelos progressivos índices de absenteísmo e de queda da produtividade (Braverman, 1977).

Não há dúvidas sobre o quanto a disseminação da disciplina taylorista, em simbiose com as linhas de produção fordistas, aprisionou, e continua aprisionando, o trabalho, esvaziando seu sentido, distanciando-o ainda mais de sua potencialidade criativa e humanizadora.

Ainda que a ideia de separação radical entre elaboração e execução seja atualmente refutada, a essência dos princípios propostos por Taylor, voltados ao controle dos trabalhadores a fim de eliminar progressivamente os poros da jornada de trabalho, mantém-se vigente, mesmo que adaptados às necessidades das formas flexíveis de organização do trabalho e da produção.

Essa constatação, no entanto, longe de nos confortar, apenas suscita um conjunto de questões: estaríamos diante de condições e situações de trabalho ainda mais adoecedoras que aquelas experienciadas no período de predomínio do taylorismo-fordismo? Como esta

\footnotetext{
2 O movimento grevista teve início entre o setor especializado do operariado, os ferramenteiros da Scania, mas, motivados pelas condições de trabalho e, sobretudo, pelo arrocho salarial, logo foi se espalhado para outras fábricas. No ano seguinte, 200 mil metalúrgicos que compunham a categoria naqueles anos aderiram ao movimento. Sobre o movimento grevista de 1978-1980, ver Frederico (1979), Antunes (1992), Oliva e Rainho (1987), entre outros.
} 
processualidade dos locais de trabalho se entrelaça com uma forma de sociabilidade que a reforça e reproduz? Quais contradições esse processo guarda?

Na perspectiva da Organização Internacional do Trabalho (2013),

...as mudanças tecnológicas e sociais, aliadas às condições da economia mundial, agravam os atuais perigos para a saúde e geram novos fatores de risco. As doenças profissionais bem conhecidas, tais como as pneumoconioses, permanecem um fenómeno generalizado, enquanto as relativamente novas, como as perturbações mentais e músculo-esqueléticas (PME), são cada vez mais frequentes (p. 4).

O objetivo deste artigo é, portanto, contribuir para a compreensão dos mecanismos presentes no ambiente de trabalho que, entrelaçados aos processos mais amplos, gerados pela sociabilidade neoliberal, tem se convertido em disparadores de processos de adoecimentos relacionados ao trabalho, com importante impacto na saúde mental.

\section{O anúncio de "novos tempos"}

Nos anos 1980, várias mudanças impactaram o mundo do trabalho. A economia e sociabilidade fundadas no taylorismo-fordismo haviam dado sinais de esgotamento desde o fim da década de 1960. Nos anos seguintes, a generalização da crise não deixou dúvidas quanto aos limites, para o capital, do modelo de sociedade construída ao longo do século XX e consolidado no pós-guerra.

O primeiro alarme que indicou que mais um ciclo de crescimento da economia mundial havia chegado ao fim soou quando a estagnação passou a alavancar o desemprego, interrompendo cerca de duas décadas de produtividade e consumo altos. A diminuição na arrecadação de impostos passou, cada vez mais, a contrastar com os gastos sociais em crescimento. A redução dos níveis de riqueza concentrados pelas classes altas e a queda da lucratividade das corporações, sentidas já ao fim dos anos 1960, também se acentuam na década seguinte, convertendo-se, conforme destaca David Harvey (2011, 2013, 2014) no gatilho para as mudanças que estariam por vir.

Harvey assinala que as mudanças vivenciadas desde então, ancoradas no ideário neoliberal, traduziram-se, em diferentes países, em práticas nem sempre análogas, mas alinhavadas em sua essência pelo imperativo do "reestabelecimento das condições de acumulação de capital", já não propiciadas pelo padrão taylorista-fordista ao final dos anos 1960. Dessa forma, o que se buscou foi, conforme o autor, a "restauração do poder das elites econômicas" (2014, p. 27). A "virada neoliberal", nesse sentido, moveu-se desde sua origem na direção do aprofundamento da exploração do trabalho. No entanto, nem todos, ao menos inicialmente, a perceberam dessa forma.

Do contexto aberto pela crise dos anos 1970 emergiram diferentes experiências que propunham superar os limites impostos pela produção seriada e em massa. Uma parcela de intelectuais, sobretudo aqueles que olharam as mudanças em curso a partir dos países centrais, viram no desenvolvimento tecnológico e em experiências alternativas de organização da produção e do trabalho possibilidades para a projeção de novos e melhores tempos para os trabalhadores.

Entre outras experiências, destacou-se a de uma unidade fabril da Volvo, na Suécia, na década de 1970, onde foram adotadas linhas de produção mais curtas, trabalho organizado a partir de equipes com relativa autonomia para decidir entre si a distribuição de tarefas, maior grau de automação objetivando ampliar a produtividade e, concomitantemente, baixar os indicadores de absenteísmo e a chamada "rotatividade voluntária" (Marx, 2010). No mesmo período também chamou a atenção a experiência conhecida como "Terceira Itália", baseada na 
formação de distritos industriais com empresas de pequeno e médio porte organizadas de forma cooperativa (Harvey, 2013; Antunes, 2015).

Autores como Adam Schaff (1990), por exemplo, passaram a defender a tese de que as então "novas tecnologias", ao possibilitarem a diminuição do tempo de produção das mercadorias, também permitiriam que o tempo dedicado ao trabalho fosse reduzido, proporcionando maior quantidade de horas voltadas ao lazer. Ainda que em curto prazo essas mudanças não atingissem o conjunto da classe trabalhadora, a ampliação do tempo livre estaria posta, conforme Schaff, como tendência intrínseca às contradições do atual estágio de desenvolvimento do sistema capitalista.

A articulação entre o desenvolvimento das tecnologias baseadas na microeletrônica e sua associação aos princípios da flexibilidade da produção e do trabalho possibilitaria também, conforme defenderam Piore e Sabel (1984), maior aproximação entre elaboração e execução, exigindo, desse modo, trabalhadores mais qualificados, tornando o trabalho mais atrativo.

Para as corporações estadunidenses e europeias, sobretudo as do ramo automobilístico, chamava a atenção, no entanto, a inserção crescente das empresas japonesas no mercado mundial. A conclusão a que chegaram, pensada em termos da concorrência do mercado, parecia óbvia: "...é preciso sair da camisa de força fordista” (Gounet, 1999, p. 17). Todavia, para fazê-lo seria também necessário convencer os assalariados dos supostos benefícios de abandonarem a "rigidez" do fordismo a favor de uma forma de organização do trabalho e da produção mais compensadora, capaz de oferecer-lhes "maiores responsabilidades" (Gounet, 1999, p. 56).

Do ponto de vista dos gestores empresariais, os discursos centraram-se em torno do resgate da criatividade do trabalho. Ao se disseminarem, nos anos 1980, juntamente com o ideário neoliberal, as novas formas de organização do trabalho e da produção, foram apresentadas como restituidoras, por meio da "valorização" e do "reconhecimento individual", da "humanização das relações de trabalho". Vale destacar o quanto a retórica difundida por meio de informativos, cartas, murais e treinamentos nos locais de trabalho passou a convergir, em seu sentido amplo, para os ideais de "liberdade" e "responsabilidade individual" propagados na sociedade como um todo.

Tal como destaca Harvey (2014), “...nenhum modo de pensamento se torna dominante sem propor um aparato conceitual que mobilize nossas sensações e nossos instintos, nossos valores e nossos desejos, assim como as possibilidades inerentes ao mundo social que habitamos" (p. 15). No período marcado pelo neoliberalismo, esse aparato passou a organizar-se a partir dos conceitos de liberdade e dignidade humana, associando sua efetivação à existência de um mercado liberto, o máximo possível, de regulações impostas pelo Estado. Os valores associados ao coletivo passam então a ceder espaço para aqueles vinculados ao indivíduo, expressos, entre outras formas, no fortalecimento da noção de meritocracia. A liberdade assume forma de bem individual. Os direitos sociais vão perdendo sua relevância frente aos direitos do consumidor.

Essa tendência, apresentada como decorrente do desenvolvimento do capitalismo, ligava-se, conforme seus defensores, tanto aos imperativos de um mercado ainda mais mundializado e competitivo como às necessidades impostas pela inserção das tecnologias informacionais. $\mathrm{O}$ mundo exigia uma força de trabalho qualificada, diziam. Mudanças dessa magnitude, por sua vez, exigiam também novas atitudes por parte dos trabalhadores. O passado deveria ser suplantado. $O$ presente exigia flexibilidade, empreendedorismo, trabalho em equipe e, sobretudo, engajamento, colaboração.

Nos escritórios, paredes foram derrubadas. Nas fábricas, especialmente nas linhas automatizadas das grandes corporações, o macacão escuro foi substituído pelas roupas claras. $\mathrm{O}$ layout dos escritórios e do setor produtivo deveria facilitar o fluxo de materiais e pessoas, mas 
também o trabalho em grupo, os "times". A analogia entre o trabalho e a prática colaborativa e competitiva presente nos esportes, proposta por Taiichi Ohno (1997), elaborador do Sistema Toyota de Produção, seria amplamente utilizada nos locais de trabalho como instrumento de persuasão, voltado à adoção de uma postura "aberta" às mudanças em curso. As mudanças deveriam começar no indivíduo, chamado a adotar uma postura aberta, flexível, colaborativa.

As equipes se tornaram o locus por excelência de outras características incorporadas pelo discurso gerencial e disseminadas dentro e fora dos locais de trabalho: ser flexível é ser, entre outras características, multifuncional e polivalente. A cooperação, no sentido atribuído por Ohno (1997, p. 42), compensa "...eventuais diferenças individuais nos tempos de operação causadas por condições físicas". Acrescenta: "O local de trabalho é como uma corrida de revezamento" (p. 44).

"Como num jogo de futebol", publicou para seus funcionários, ao fim da década de 1990, uma das automobilísticas instaladas no Brasil, "...todos os empregados, de todos os setores, devem ter o mesmo objetivo: marcar pontos, ou seja, vencer as dificuldades e tornar a Volkswagen mais competitiva. A tarefa está em nossas mãos. Cada empregado pode contribuir. Basta querer" (O Parceiro, n. 47, 1999). Alguns anos antes, logo no início do processo de reestruturação de duas de suas unidades fabris mais antigas ${ }^{3}$, a mesma corporação, em um boletim voltado para os supervisores e líderes, insistia em uma dada noção de "eficiência", desdobrada dos preceitos de "melhorias contínuas" e "qualidade total", advindos do toyotismo, mas aos poucos incorporados às práticas fora dos locais de trabalho.

Quando as pessoas partem da premissa que errar é humano, cria-se permanentemente uma justificativa para todos os erros, as falhas, os desperdícios, já que esses erros são ditos como da natureza humana.

Ora, as pessoas acertam muito mais que erram. Se isso não fosse verdade, o homem já teria desaparecido da Terra.

Esse dito popular pode muito bem ser alterado para um outro muito mais próximo da natureza humana: acertar é humano.

Aceitando isso, valorizamos os acertos de todos, reconhecendo a contribuição de cada um, que certamente é infinitamente superior aos erros cometidos.

Pensem nisso! (Volkswagen, 1995).

O desafio, no entanto, mantinha-se. Era necessário convencer os assalariados de que novos e melhores tempos se anunciavam para o mundo do trabalho. Não se tratava de um capricho, mas de uma condição essencial. Sem envolvimento, sem engajamento, as novas formas de organização do trabalho e da produção não funcionariam, já que estavam ancoradas no trabalho em equipe, na polivalência e multifuncionalidade, na incorporação formal do saber do trabalhador às estratégias corporativas e, sobretudo, na assimilação, por parte do trabalhador, da responsabilidade pela competitividade da empresa.

Um passo importante no sentido de envolver os trabalhadores nas mudanças que estavam por vir foi dado com a adesão de parte das lideranças de esquerda ao projeto das corporações. A participação das entidades sindicais nas alterações no local de trabalho, adotadas inicialmente no setor automobilístico, passou a ser parte importante do processo de reestruturação produtiva em diferentes países. Negociar as mudanças no "chão de fábrica", instituir espaços de participação dos trabalhadores, discutir a competitividade da empresa frente a seus concorrentes e incidir sobre o modelo de desenvolvimento da sociedade foram demandas incorporadas à pauta sindical de tal forma que parte da representação dos trabalhadores passou a crer que a democracia entre capital e trabalho havia, enfim, se 
estabelecido ${ }^{4}$ (Antunes, 2000; Antunes \& Praun, 2015; Gounet, 1999; Linhart, 2007; Praun, 2012).

A repercussão e abrangência das mudanças tornam-se visíveis já nos anos 1980. Por um lado, a explosão do desemprego e da informalidade articulada à contínua desregulamentação de direitos do trabalho e à proliferação de diferentes formas de vínculos contratuais ${ }^{5}$, por outro, $\mathrm{o}$ aumento significativo da produtividade e intensidade do trabalho, ancoradas nos diferentes mecanismos de controle e pressão vivenciados dentro e fora do ambiente laboral.

Em uma sociedade na qual o trabalho, em diferentes dimensões, possui centralidade, a maneira como ele se ordena também tece as formas assumidas pelo viver junto. Observar essas formas, valendo-se da possibilidade do olhar retrospectivo, traz à tona o quanto a fase aberta a partir da crise dos anos 1970, ao aprofundar a degradação do trabalho (Antunes, 2013), promove concomitantemente, "...a intensa degradação do viver-junto em coletividade" (Dejours \& Bègue, 2010, p. 21).

Os sinais do mal-estar dentro e fora dos locais de trabalho logo puderam ser percebidos, entre outras formas, pelos índices crescentes de formas específicas de adoecimentos, entre elas as doenças osteomusculares e os transtornos mentais (OIT, 2013), assim como as crescentes ocorrências de suicídios com nexo laboral (Dejours \& Bégue, 2010).

\section{Entre o improviso e a criatividade controlada}

Ao reduzir o trabalho a mero movimento repetitivo, a gerência científica explicitou uma faceta da exploração do trabalho nem sempre evidente no período que a antecedeu: a rotina destrói lentamente a saúde porque esvazia o trabalho de sua essência humana.

Sob o predomínio do taylorismo-fordismo, o capital buscou disciplinar e controlar corpo e mente do trabalhador. A disciplina imposta ao corpo, ditada pela cadência dos movimentos simplificados e repetitivos, trouxe consigo a tentativa de controle da mente, mas de uma forma distinta daquela com a qual passamos a conviver na fase atual. Sob a vigência do taylorismo-fordismo, a mente já não deveria emprestar aos gestos a engenhosidade do corpo de quem trabalha.

A ideia de engenhosidade aqui exposta aproxima-se da noção de inteligência inventiva, criativa, proposta pela Psicodinâmica do Trabalho. Para Dejours (2012a), a inteligência inventiva resulta de um processo de mobilização subjetiva no qual o corpo, confrontado com o real por meio do trabalho, se apropria do mundo, desenvolvendo e incorporando um saber-fazer nem sempre perceptível. Mais que mera atividade individual, o trabalho se constitui em relação social, já que pressupõe um engajamento subjetivo que se efetiva na relação do sujeito com o mundo. Este mundo, marcado por suas hierarquias, ordenamentos, constrangimentos, e "...ainda perpassado pela luta de dominação", desafia o trabalhador a encontrar soluções, caminhos para a realização, assim como sentido para seu trabalho (Dejours, 2012b, p. 36). Quando essas possibilidades se apresentam bloqueadas, o trabalho tende a se constituir em fonte de adoecimento.

Não à toa o contexto do taylorismo-fordismo chama a atenção pela explosão dos processos de adoecimento entre os trabalhadores. Por meio do controle dos gestos, do domínio do tempo de trabalho, a gerência científica impactou profunda e negativamente a saúde dos

4 Essa perspectiva, também presente em parte da produção acadêmica brasileira na década de 1990, constituiu-se na base teórica para elaboração política e atuação de um conjunto de sindicatos agrupados no interior de uma das principais centrais sindicais brasileiras, a CUT. Nos anos 1990, a central foi protagonista de um modelo de sindicalismo, propositivo, que considerava que o engajamento dos trabalhadores no processo de reestruturação produtiva, negociando cada aspecto das mudanças em curso, seria capaz de possibilitar um maior controle, por parte dos trabalhadores, sobre o processo de trabalho, assegurando ainda a manutenção dos postos de trabalho (Antunes, 2015; Galvão, 2012; Praun, 2006, 2012). 
trabalhadores, tal como expressa o relato de Robert Linhart (1980) sobre a rotina das linhas de montagem da Citroën nos anos 1970:

Era um negro, muito forte, que falava francês com dificuldade, mas que conseguia exprimir-se de qualquer jeito. Seu trabalho consistia em aparafusar uma peça do painel de controle com uma chave de fenda. Cinco parafusos a colocar, em cada carro. Numa sexta-feira, à tarde, estava no quingentésimo parafuso do dia. De repente começou a gritar e precipitou-se sobre os paralamas dos carros, brandindo sua chave de fenda como um punhal. Dilacerou cerca de uma dezena de carroçarias antes que um grupo de blusões brancos e azuis acorresse às pressas para dominá-lo e levá-lo, ofegante e gesticulando, até a enfermaria (p. 49).

Situações como as relatadas acima foram consideravelmente discutidas entre os pesquisadores, especialmente a partir da segunda metade do século XX. A necessidade de revisitá-las, entretanto, tem por objetivo responder parcialmente a uma das questões que este artigo busca problematizar: o trabalho e as relações de trabalho que emergem nos anos 1980 configuram-se como mais adoecedoras que aquelas experienciadas no período de predomínio do taylorismo-fordismo?

Uma das pistas para responder a essa questão consiste na admissão de que, sob o predomínio do taylorismo-fordismo, subsistiu, para uma parcela importante de trabalhadores, uma pequena margem para a autonomia, o improviso e a engenhosidade que caracterizam o trabalho humano.

Essa margem, não consentida, fruto do princípio da separação entre elaboração e execução, viabilizou-se a partir de diferentes fatores, todos típicos do contexto histórico de desenvolvimento da produção em massa e seriada. Entre eles, deve-se considerar que as jornadas de trabalho longas e exaustivas, organizadas sob a lógica dos altos estoques, podiam oscilar, ao longo dos meses, entre momentos de maior e menor produtividade. Por outro lado, apesar de parte dos trabalhadores ter passado a conviver, sobretudo entre os anos 1950-1970, com ambientes de trabalho cada vez mais automatizados, eles guardam uma enorme distância daqueles que conhecemos na atualidade, com um potencial de controle sobre o trabalho e de ampliação de sua produtividade e intensidade nunca experimentado antes ${ }^{6}$.

Vale destacar ainda que “...a própria ideia de separação entre elaboração e execução, base do taylorismo-fordismo, ao negar formalmente o conhecimento cotidiano produzido pelos trabalhadores, dota o trabalho de certa autonomia frente à gerência". No mesmo sentido opera "...a forte especialização dos trabalhadores no desenvolvimento de suas tarefas", característica típica do fordismo (Praun, 2016, p. 29). Contraditoriamente, portanto, observa-se a persistência do domínio de um saber-fazer não necessariamente compartilhado com a gerência, tal como destaca Dejours (2012).

É nesse contexto que tanto o trabalho manual como o caracterizado como intelectual, seja pelo desejo de "atingir os objetivos que lhe são confiados", pelo prazer de fazer bem feito (Dejours, 2012, p. 38), ou pela burla, capaz de aliviar o peso dos esforços impostos por jornadas de trabalho extenuantes, puderam valer-se, em muitas ocasiões, dos espaços para o improviso e engenhosidade, a exemplo do que relata Linhart (1980) ao referir-se à sua própria experiência nas linhas de montagem da Citroën:

No serviço por produtividade tinha arranjado uma pequena tática individual para enganar o tempo: acelerava, ia mais devagar, um esforço mais intenso pela manhã ao começar o trabalho, um ritmo mais tranquilo antes da refeição e durante a digestão, aumentos de velocidade para quebrar a monotonia (p. 42).

Histórias similares às vivenciadas por Linhart podem ser escutadas no $\mathrm{ABC}$ Paulista, nas conversas travadas entre os operários da geração dos anos 1970-1980. São histórias sobre

6 O controle do trabalho atual, bem mais sofisticado, identifica, no caso da indústria automobilística, o tempo de paralisação nas linhas de montagem, a produtividade mensal da força de trabalho, o custo de produção de peças defeituosas, o tempo e custo com retrabalho, o percentual de absenteísmo, entre outros aspectos (Praun, 2016). 
burlas para aliviar o tempo da jornada e que envolvem, entre outras artimanhas, desde mover os ponteiros metálicos dos antigos relógios de ponto com um imã, para antecipar ou retardar o horário de marcação de ponto, a organizar as tarefas de forma a instituir pequenos intervalos de descanso nos vestiários. Não menos comuns são os relatos sobre o orgulho de ser um bom pintor, marceneiro, torneiro ou uma boa operadora de máquinas, atendente, diarista, professora etc.

Contudo, as pequenas transgressões, as margens para o improviso, assim como a existência dos pequenos poros nas jornadas de trabalho são aspectos cuja importância só pôde ser realmente percebida quando a disseminação da produção e trabalho flexíveis completou seu primeiro ciclo, nos anos 1990.

Sob o predomínio da organização flexível da produção e do trabalho, as habilidades, macetes, artimanhas adquiridas tanto pela experiência individual como pelas trocas entre trabalhadores passaram a ser vistas como um poderoso mecanismo voltado a rever procedimentos, reduzir o tempo das operações, diminuir a incidência de erros, alimentar os sistemas automatizados, aumentando tanto a produtividade como a intensidade do trabalho ${ }^{7}$ (Antunes \& Praun, 2015; Dal Rosso, 2008; Praun, 2016).

O saber do trabalhador, incorporado às estratégias corporativas, assumiu a forma do que passamos a conhecer como processos de melhorias contínuas e qualidade total. Pensar em termos de qualidade total, sob a lógica da organização do trabalho e produção flexibilizada, pressupõe, entretanto, conceber o processo de trabalho como algo em permanente ajuste e adaptação. Implica, conforme Dejours (2008), instituir novos “...constrangimentos ao trabalho prescrito, tornando ainda mais rígidos os procedimentos e controles” (p. 69).

Por outro lado, ao converter o não formalizado em obstáculo à competitividade da empresa, o cerne do processo de trabalho passou a girar em torno da colaboração tanto do trabalhador enquanto indivíduo como dele enquanto integrante dos times ou equipes de trabalho.

A colaboração, princípio das formas de organização do trabalho e produção flexíveis, longe de refletir um pequeno indício de democratização das relações entre capital e trabalho, visou apenas, conforme salienta Danièle Linhart (2007) "...criar as condições da eficiência tecnológica..." a partir do uso maximizado da "...capacidade e (...) conhecimentos dos trabalhadores" (p. 87).

\section{O sucesso da empresa depende de todos}

A estrutura de equipes (ou times) que passou a ordenar as relações no interior das grandes corporações, repercutindo nas empresas de menor porte, compõe um sistema integrado no qual cada equipe, ao mesmo tempo em que compete com as demais, opera no sentido de colaborar para o aumento da produtividade e intensidade do trabalho na empresa como um todo. A alteração nos procedimentos de trabalho em um grupo, seja por pequenas mudanças na forma de execução ou pela inserção de tecnologia, tende a repercutir tanto em termos do resultado que se pretende obter como em termos de tempo e energia empregados na tarefa por todos os demais grupos.

Na essência dessas operações, impulsionadas por um poderoso sistema de controle que envolve desde os programas de avaliação individual e coletiva às metas de trabalho, quase sempre acompanhadas dos sugestivos prêmios e bonificações, assenta-se a ideia de empresa competitiva.

7 "Não existe nada melhor do que poder colaborar com pequenas sugestões, pequenos projetos e ideias, que somados, farão grande diferença para a competitividade da Companhia", alertava, no fim da década de 1990, um informativo da Volkswagen (1990) dirigido aos trabalhadores do chão de fábrica. 
Mas qual o sentido assumido pela competitividade de uma empresa no cenário construído a partir dos anos 1980? Uma empresa competitiva é, entre outros fatores ${ }^{8}$, aquela cujas diferentes unidades, espalhadas em distintos pontos de um país ou do globo, ao serem isoladamente competitivas, dotam-na de condições concorrenciais superiores às demais.

É neste contexto que o envolvimento das lideranças sindicais no processo de reestruturação, por meio da prática das contrapartidas ${ }^{9}$, assume papel primordial. O movimento, desencadeado em locais de trabalhos específicos, onde as equipes concorrem e colaboram entre si, ampliando a intensidade e produtividade do trabalho, reproduz-se no mercado mundializado tanto entre as unidades diferentes de uma mesma empresa como entre empresas concorrentes, ampliando a exploração do trabalho em escala global.

Nesse ambiente, a antiga gerência, ocupada em grande medida com o controle burocrático dos recursos humanos, reinventa-se e passa a dedicar-se à gestão de pessoas. As preocupações, no contexto da reestruturação produtiva, direcionam-se para como viabilizar, valendo-se da mobilização direta e subjetiva de todos, a inserção e manutenção da empresa no mercado. A gestão gerencialista, conforme Gaulejac (2007), “....apresenta-se como pragmática ... fundada sobre a eficácia da ação, mais do que sobre a pertinência das ideias” (p. 63). Organizada a partir de metas, todos são direcionados para buscar soluções. $\mathrm{O}$ espaço para a crítica desaparece. Todos devem ser "proativos".

Voltada fundamentalmente para obtenção de resultados, a gestão, estruturada a partir dos times de trabalho, penetra, articula e direciona o conjunto das atividades desenvolvidas dentro e fora do trabalho. O paradoxo, entretanto, é que, em meio à exaltação do trabalho em equipe, o que sobressai é o indivíduo, isolado de seus pares, objeto de constantes avaliações e fonte da eficácia em um ambiente de trabalho moldado pela racionalidade neoliberal. Ao final, destaca Dejours (2012a), “...cada um se encontra só, no meio da multidão, em um ambiente humano e social com características de hostilidade. A solidão e abatimento se instalam no mundo do trabalho e isso muda radicalmente o cenário no que diz respeito à relação subjetiva frente ao trabalho e à saúde mental" (pp. 28-29).

Dados sobre custos de produção, posição da empresa concorrente, pedidos, indicadores de qualidade a serem atingidos, resultados a serem alcançados, expostos a partir de planilhas, informativos, painéis, passam também a fazer parte do dia a dia do trabalho. Todos passam a ser responsáveis pelo desempenho da empresa, interiorizando seus riscos, assumindo-os como seus.

Os instrumentos de gestão por metas, conforme ressalta Gaulejac (2007), “...dão o sentimento a cada assalariado de ser tratado como os outros" (p. 101), fazendo-o crer que seu trabalho está sendo avaliado com objetividade, de maneira individualizada, sugerindo que cada um é responsável pelo seu próprio desempenho e pela chance de ascender profissionalmente. Esse sentimento de valorização, importante para a construção dos laços de confiança entre trabalhador e corporação, está na base da noção de eficácia, também bastante disseminada dentro e fora dos locais de trabalho.

Alcançar os resultados esperados encontra-se também em sintonia com o que Linhart (2000) denominou como individualização do trabalho. Aqui, novamente a estrutura corporativa organizada a partir dos times ganha destaque, já que a individualização tem como um de seus pontos de apoio a diminuição dos níveis hierárquicos e a "mudança da natureza da supervisão". Esta passa cada vez mais a assumir "...funções de animação e gestão, mais do que as de

8 Entre esses fatores encontram-se aqueles relativos à sua capacidade de inserção em uma economia mundial fortemente marcada pela financeirização.

9 Os processos reestruturação negociada pressupõem, constantemente, que os trabalhadores de uma unidade fabril abram mão de direitos garantidos em acordos coletivos anteriores ou aceitem modificações nos pisos salariais, terceirização parcial ou total de setores, entre outras medidas, em troca de investimentos da corporação na unidade em que a negociação está sendo realizada. Essa prática, que condiciona os investimentos da corporação em uma determinada unidade à construção de condições favoráveis de competitividade, tem fragilizado a reação dos trabalhadores frente à acentuação dos processos de precarização do trabalho (Praun, 2006, 2012). 
comando" (2000, p. 29), favorecendo a constituição de um ambiente de trabalho que pressiona, de forma difusa, para a adesão às regras do jogo. Aderir, por sua vez, implica trabalhar "...a si mesmo para se tornar mais produtivo", de forma a "...tornar a empresa - que é a entidade de referência - mais produtiva” (Dartdot \& Laval, 2016, p. 343).

As injunções típicas da sociabilidade neoliberal, expressas no cotidiano do trabalho, entretanto, chocam-se constantemente com as ambições suscitadas pela colaboração, pressuposto das novas formas de gestão. Tornar a si mesmo mais produtivo, dotando a empresa de maior produtividade, entra em confronto com a própria capacidade humana de suportar demandas, ritmo e intensidade de trabalho crescentes.

Por outro lado, a própria dinâmica excludente que move a empresa opera no sentido inverso às ambições suscitadas pela colaboração. Para ser competitiva, ela deve ser enxuta. Para assim tornar-se, precisa constantemente derrubar as barreiras que limitam sua lucratividade. Derrubar essas barreiras, por sua vez, desdobra-se em criar formas, sem limites, de tornar o trabalho cada vez mais flexível, precário e descartável.

Essa ausência de limites, longe de configurar uma abstração, vem assumindo formas bem palpáveis. Contra a "rigidez" e "monotonia" das relações de trabalho vigentes no período anterior, surgem variações múltiplas tanto para os contratos de trabalho como para a jornada. Experiências como a da General Motors, no Equador, que chegou a contratar operários por dia de trabalho, ou os chamados contratos zero-hora ${ }^{10}$, permitidos no Reino Unidos desde os anos 1980, em franca expansão a partir de 2008, assim como a legislação que institui o trabalho intermitente, em discussão no Brasil, sinalizam que nos "novos tempos", marcados pelas relações flexíveis, o tempo livre não raramente é a expressão mais visível da precarização do trabalho.

É neste contexto, marcado pela crescente individualização, insegurança, instabilidade, medo e fragilização dos laços coletivos, que um amplo contingente de trabalhadores vem desenvolvendo, entre outras formas de adoecimento, aquelas classificadas como transtornos mentais.

A incidência crescente dessas ocorrências, conforme apontam as estatísticas brasileiras e os estudos da OIT (2013), quando analisada à luz das mudanças que impactaram as relações de trabalho nas últimas décadas do século XX, e seguem se aprofundando no contexto atual, nos fornecem pistas valiosas para refletir sobre as tendências e desafios que se desenham para o mundo do trabalho.

\section{Considerações finais}

Richard Sennett (2006), ao analisar os impactos pessoais que resultaram da forma assumida pela sociabilidade capitalista nas últimas décadas do século $\mathrm{XX}$, salientou a flexibilidade como elemento articulador de um ser e estar no mundo marcado pela provisoriedade. A vida pensada a partir de relações e vínculos duradouros tornou-se para o sistema, ressalta o autor, disfuncional. A rotina, antes estruturadora das relações de trabalho de parcela importante da classe trabalhadora, foi cedendo espaço, rapidamente, para uma sociabilidade que, adequada às necessidades de uma economia cada vez mais competitiva e financeirizada, acelerou o tempo social, trazendo para o cotidiano daqueles que vivem do seu trabalho o medo e a insegurança.

O vislumbre de aposentar-se ao fim de uma jornada de décadas de trabalho foi aos poucos evaporando diante dos olhos. Junto com ele foram sendo consumidas as esperanças de

$10 \mathrm{O}$ contrato zero-hora vale-se da disponibilidade integral do trabalhador. A quantidade de horas a serem cumpridas, assim como em qual período do dia, é muitas vezes comunicada no próprio dia de trabalho, sem qualquer garantia de jornada ou remuneração mínima (Maeda, 2016). 
mobilidade social idealizadas nas sociedades capitalistas do Ocidente, sobretudo nos países centrais, entre os anos 1950-1970. A ideia de deixar, além da herança moral, algum bem material capaz de auxiliar os filhos nos primeiros passos da vida adulta, de encaminhá-los para carreira relativamente estável, também, aos poucos foi sendo tomada pelo sentimento de incerteza.

Conforme salienta Sennett (2006), “...dificilmente nos dispomos hoje a pensar no tempo rotinizado como uma conquista pessoal, mas em vista das tensões, prosperidades e depressões do capitalismo industrial, foi o que se tornou. (...) A rotina pode degradar, mas também pode proteger; pode decompor o trabalho, mas também compor uma vida" (pp. 4849).

A vida projetada ao curto prazo, típica da sociabilidade nascida da crise dos anos 1970, implica vínculos pessoais e de trabalho contingenciais. Estes, por sua vez, se, por um lado, se encontram em sintonia com um conjunto de dispositivos capazes de acelerar o tempo de giro da produção e consumo, por outro, tendem a se constituir em fonte adoecimento físico e mental. O tempo cada vez mais acelerado do mercado está longe de equivaler-se ao tempo das necessidades da vida humana.

Este artigo buscou contribuir para a compreensão do impacto e da abrangência das mudanças em curso desde os anos 1970-1980, marcadas pelos pressupostos da gestão flexível, na saúde dos trabalhadores. As reflexões apresentadas foram conduzidas pelo questionamento sobre se estaríamos ou não diante de uma forma de organização do trabalho e sociabilidade ainda mais adoecedoras que a anterior, marcada pela vigência do padrão taylorista-fordista. Trata-se, sem dúvida, de uma questão em aberto, à qual outras podem ser acrescidas.

As mudanças em curso no mundo do trabalho atingiram, de forma importante, os laços de solidariedade de classe, fundamentais para que sejam impostos limites à deterioração das condições de vida e trabalho. Quais limites se impõem a uma forma de sociabilidade que se reproduz em base à crescente degradação do trabalho e das formas do viver junto? Em que medida mudanças tão profundas, desencadeadas em escala global, ainda que em ritmos e formas diferenciadas, podem contraditoriamente possibilitar bases novas e ampliadas para uma coletividade que seja capaz projetar outra sociabilidade, fundada no resgate do trabalho como atividade criativa? Enfim, as questões apresentadas neste artigo inserem-se no marco de um campo aberto a novas investigações.

\section{Referências}

O Estado de S. Paulo (1979). ABC, onde a idade não define a velhice. O Estado de S. Paulo. São Paulo, 29 jan.

Antunes, R. (1992). A rebeldia do trabalho. O confronto operário no ABC Paulista: as greves de 1978/80. Campinas, SP: Editora da Unicamp.

Antunes, R. (2015). Adeus ao trabalho? Ensaio sobre as metamorfoses e a centralidade do mundo do trabalho. (ed. especial de 20 anos). São Paulo: Cortez.

Antunes, R. (2010) Os sentidos do trabalho: ensaio sobre a afirmação e a negação do trabalho. São Paulo: Boitempo.

Antunes, R. (2013). A nova morfologia do trabalho e suas principais tendências. In: R. Antunes (Org.), Riqueza e Miséria do Trabalho II (pp. 13-27). São Paulo: Boitempo.

Antunes, R. (Org.) (2014). Riqueza e miséria do trabalho III. São Paulo: Boitempo.

Antunes, R. \& Praun, L. (2015). A sociedade dos adoecimentos no trabalho. Serviço Social Eु Sociedade, 123, 407. 427.

Braverman, H. (1977). Trabalho e capital monopolista: a degradação do trabalho no século XX. Rio de Janeiro: Zahar.

Clot, Y. (2010). A psicologia do trabalho na França e a perspectiva da clínica da atividade. Fractal: Revista de Psicologia, 22 (1), 207-233.

Dal Rosso, S. (2008). Mais trabalho! A intensificação do labor na sociedade contemporânea. São Paulo: Boitempo. 
Dardot, P. \& Laval, C. (2016). A nova razão do mundo: ensaio sobre a sociedade neoliberal. São Paulo: Boitempo.

Dejours, C. (1992). A loucura do trabalho: estudo de psicopatologia do trabalho. São Paulo: Cortez-Oboré.

Dejours, C. (2008). A avaliação do trabalho submetida à prova do real. In: L. I. Sznelwar \& F. L. Mascia (Orgs.), Cadernos TTO. São Paulo: Blucher.

Dejours, C. \& Bègue, F. (2010). Suicídio e trabalho: o que fazer? Brasília: Paralelo 15.

Dejours, C. (2012a). Sexualidade e trabalho. Trabalho vivo, Tomo I. Brasília: Paralelo 15.

Dejours, C. (2012b). Trabalho e tmancipação. Trabalho vivo, Tomo II. Brasília: Paralelo 15.

Engels, F. (2010). A formação da classe trabalhadora na Inglaterra. São Paulo: Boitempo.

Frederico, C. (1979). A vanguarda operária. São Paulo: Edições Símbolo.

Galvão, A. (2012). De "laboratório" das relações de trabalho a formulador da política nacional: o Sindicato dos Metalúrgicos do ABC paulista. In D. C. Souza \& P. V. Trópia (Orgs.), Sindicatos dos Metalúrgicos no Brasil Contemporâneo (pp.135-161). Belo Horizonte: Fino Traço.

Gaulejac, V. (2007). Gestão como doença social: ideologia, poder gerencialista e fragmentação social. Aparecida, SP: Ideias e Letras.

Gounet, T. (1999). Fordismo e toyotismo na civilização do automóvel. São Paulo: Boitempo.

Harvey, D. (2011). O enigma do capital e as crises do capitalismo. São Paulo: Boitempo.

Harvey, D. (2013). Condição pós-moderna. São Paulo: Loyola.

Harvey, D. (2014). O Neoliberalismo: história e implicações. São Paulo: Loyola.

Le Guillant, L. et al. (2006). A neurose das telefonistas. In M. E. A. Lima (Org.), Escritos de Le Guillant: da ergoterapia à psicopatologia do trabalho (Pp. 175-188). Petrópolis, RJ: Vozes.

Linhart, D. (2000). O indivíduo no centro da modernização das empresas: um reconhecimento esperado, mas perigoso. Revista Trabalho E̊ Educação, 7, 24-36.

Linhart, D. (2007). A desmedida do capital. São Paulo: Boitempo.

Linhart, R. (1980). A greve na fábrica. Rio de Janeiro: Paz e Terra.

Maeda, P. (2016). Trabalho no capitalismo pós-fordista: trabalho decente, terceirização e contrato zero-hora. Dissertação de Mestrado. Programa de Pós-Graduação em Direito, Departamento de Direito do Trabalho e da Seguridade Social, Universidade de São Paulo.

Marx, K. (2013). O capital. Livro I. São Paulo: Boitempo.

Marx, R. (2010). Trabalho em grupo e autonomia como instrumentos de competição. São Paulo: Atlas.

Ohno, T. (1997). O sistema toyota de produção: além da produção em larga escala. Porto Alegre: Bookman.

Oliva, A. M. \& Rainho, L. F. (Orgs.) (1987). Imagens da luta: 1905-1985. São Bernardo do Campo, SP: Sindicato dos Trabalhadores nas Indústrias Metalúrgicas, Mecânicas e de Material Elétrico de São Bernardo do Campo e Diadema.

Organização Internacional do Trabalho. (2013). A Prevenção das Doenças Profissionais. Genebra.

Praun, L. (2006). Reestruturação negociada na Volkswagen, São Bernardo do Campo. In R. Antunes (Org.), Riqueza e miséria do trabalho no Brasil (pp. 155-178). São Paulo: Boitempo.

Praun, L. (2012). Sindicalismo metalúrgico no ABC paulista: da contestação à parceria. In D. C. Souza \& P. V. Trópia (Orgs.), Sindicatos metalúrgicos no Brasil contemporâneo (pp. 109-134). Belo Horizonte: Fino Traço.

Praun, L. (2016). Reestruturação produtiva, saúde e degradação do trabalho. Campinas, SP: Papel Social.

Piore, M. J. S. \& Sabel, C. F. (1984). The second industrial divide: possibilities for prosperity. New York: Basic Books.

Ramazzini, B. (2000) As doenças dos trabalhadores. São Paulo: Fundacentro.

Seligmann-Silva, E. (2011). Trabalho e desgaste mental: o direito de ser dono de si mesmo. São Paulo: Cortez.

Sennett, R. (2006). A corrosão do caráter: consequências pessoais do trabalho no novo capitalismo. São Paulo: Record.

Schaff, A. (1990) A sociedade informática. São Paulo: Unesp.

Taylor, F. W. (1995). Princípios de administração científica. São Paulo: Atlas.

Volkswagen. (1995). Para reflexão. RH 2000. Em busca da excelência através das pessoas, 2, 31 jul. 
Volkswagen. (1999). Ligando o motor da criação. O Parceiro, 45, jun.

Volkswagen. (1999). Uma nova postura frente às dificuldades. O Parceiro, 47, ago.

Volkswagen. (2001). Use a imaginação. O Parceiro, 74, set.

\section{Endereço para correspondência}

lupraun@uol.com.br

Recebido em: 02/02/2017

Revisado em: 15/07/2017

Aprovado em: 19/07/2017 